\title{
Optimization of technical solutions for pilot hole drilling in soil
}

\author{
Boris Danilov ${ }^{1, *}$, and Boris Smolyanitskiy ${ }^{2}$ \\ ${ }^{1}$ N.A. Chinakal Institute of Mining, Siberian Branch, Russian Academy of Sciences, 630060 \\ Novosibirsk, Russia \\ ${ }^{2}$ Siberian Transport University, 630049 Novosibirsk, Russia
}

\begin{abstract}
The paper discusses approaches to improvement of equipment for borehole drilling with a predetermined trajectory in construction of underground utility systems and facilities. Piercing method allows implementing dry drilling of boreholes with small diameter using simple technical equipment. The methods used when preparing the research are analysis, generalization, and experimental research methods. Outcomes of the research include evidence that increase in performance of vibro-impact piercing is possible not only due to higher impact energy, but also due to optimization of interaction between the operating tool and soil. Combination of dynamic action by impact pulses and static forces applied to the drilling equipment enables to enhance performance of impact pulse action and increase the drilling speed. Accuracy of the borehole trajectory can be provided by using dynamic stabilizers or correcting the drilling direction due to asymmetrical tool shape in combination with the torque moment of a drilling equipment. The study formulates requirements to design of a drilling unit for directed pilot hole drilling by dynamic piercing method. The design of an improved pneumatic tool installed in front of the drill string and equipped with asymmetrical front head is described. Experimental research results are given on the process of a borehole drilling using the described tool.
\end{abstract}

\section{Introduction}

Borehole drilling in the rock mass is an important part of the upstream technologies for mineral deposits. Boreholes are widely used in underground development for utilities installation without opening daylight surface, roof bolting, installing pile foundations, reinforcing soil structures and other technological processes [1]. In underground development, borehole drilling is mostly performed in soil. Since soil compaction may occur under mechanical action, such methods as piercing and direct push techniques are widely practiced, which are based on static or dynamic driving of an operating tool into soil without rotation [2]. Due to simplicity and efficiency these techniques became the basis of trenchless technologies for underground utilities installation on the early stage of their development.

\footnotetext{
* Corresponding author: bbdanilov@mail.ru
} 
The main drawbacks of these techniques are poor performance and insufficient accuracy of borehole location in the defined underground area. For that reason, in recent times trenchless technologies are mostly connected with horizontal directional drilling (HDD) $[3,4]$. Effective control of the installation trajectory with HDD equipment is achieved by using asymmetrical drill, and ground breaking is performed hydraulically. The latter condition empirically proved this technique inappropriate for urban use. Drilling mud is supplied in the borehole under pressure, it inevitably causes geometric inconsistencies while borehole forming which are hard to control. Such inconsistencies lead to daylight surface subsidence which is totally unacceptable when installing utilities under roads, highways and other constructions $[5,6]$.

Therefore, the task for developing trenchless technologies consists in increasing performance and accuracy of borehole location in the defined underground area with compliance to safety requirements for adjacent infrastructure and natural environment. Methods based on impact techniques of borehole formation are the most promising. They potentially enable to significantly increase drilling speed without the increase of operational resources of technical equipment [7]. However, impact machines are the source of vibrations and noise and therefore the preferable direction of the technology development is achievement of the effect not by increasing the impact energy of the machines, but due to optimization of interaction between the operating tools and soil [8]. These processes are insufficiently studied, while having high potential for increasing performance of impact pulse action for moving the operating tool [1]. Using these potential reserves will enable to significantly improve technical and economic parameters of the studied technological processes and develop novel mixed technologies combining different drilling methods.

\section{Research methods}

In the process of study the following methods were used: analysis, comparison, consolidation of information, experimental research and parameters measurement. This set of chosen methods can be explained by the fact that soils possess a wide range of physicomechanical properties, and to obtain complete and reliable information on the process of interaction between the operating tool and soil both theoretical and experimental methods are required. Analysis of the existing borehole drilling techniques and equipment allows distinguishing peculiarities of technological processes and assessing their improvement possibilities. As a result of consolidation of this information the directions and perspectives for trenchless technologies were substantiated. Efficiency of the suggested solutions was experimentally verified, the obtained results are formulated in the conclusions.

Analysis of specific features of technological processes that take place in the modern dry drilling equipment with no fluid used demonstrates that in most cases borehole is formed in two stages. At the first stage a pilot hole with a small diameter is drilled which sets the required trajectory. After that it is reamed up to the required diameter by further drilling. In some cases, third stage is carried out which includes extraction of casing, mostly metal one, and installation of a kelly made of plastic, reinforced concrete, etc.

This principle is used in operation of auger drilling units which recently got a new development impulse due to solving the issue of drilling trajectory control. Typically, it is provided by preliminary drilling of a pilot hole with a small diameter [9]. Such units have an operating tool for piercing a pilot hole with a predetermined trajectory, a rotary drilling tool for further reaming and a screw conveyor for soil excavation, as well as drivers for operating tool, casing and kelly. The most widespread are the following models and brands: Richmond, WIR, Astec Underground, Bohrtec and Herrenknecht, HEB 1 and Taifun by Schmidt, Kranz \& Co., GmbH, Perforator, etc. 
The first stage - pilot hole drilling - is carried out using piercing method from the entry pit (Fig.1) where a hydraulic jack is installed which presses soil into the drill pipe with a wedge bit. When pressing the drill pipe the wedge provides deviation from the direct trajectory. This deviation is recorded by a control device and is eliminated by reverse rotation of the wedge inclined surface during the drill pipe penetration. The occurring deviation is compensated in the same manner. Pressing of a drill pipe is carried out until the bit reaches the intake pit. The process is controlled by a laser control system. In spite of a slightly wavelike trajectory, the borehole usually reaches the predetermined area.

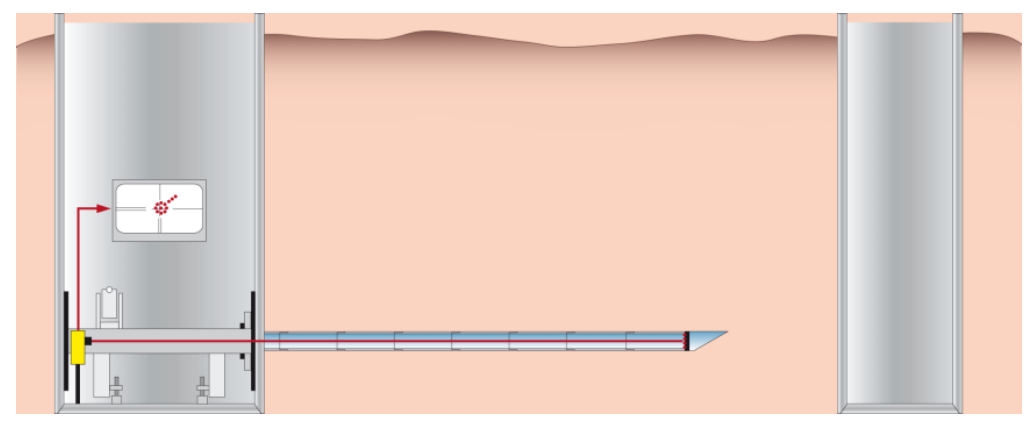

Fig. 1. Drilling of a pilot hole in compacting soil without drill string rotation.

It shall be noted that such pilot hole drilling method is only applicable for compacting soils. Its main drawback is high energy consumption while forming a borehole space due to static manner of pressing action [10].

Vibro-impact piercing is the simplest and rather efficient method which was developed in the 1970s - 1980s, when reliable pneumatic impact machines called pneumodrifts were designed at the Institute of Mining, Siberian Branch of the Russian Academy of Sciences [11]. Controlled pneumodrift independently moving in the soil enables to avoid using drilling unit at the first stage of technological process, which provides considerable cut of operational costs.

An important requirement when drilling a borehole in compacting soil for installing underground utilities in most cases is its straightness and reaching the predetermined area. However, both static and dynamic operating tools almost always have certain deviations from the set direction. The main reason for that being inhomogeneity of soil, among many others.

Accuracy of borehole drilling can be achieved by extending the length of calibrating section of the operating tool, for example, pneumodrift, or by its equipment with stabilizers (Fig.2) [11].

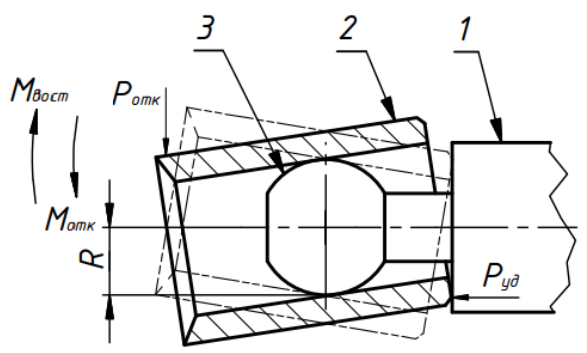

Fig. 2. Principle of operation of a dynamic stabilizer: 1 - body of pneumodrift; 2 - cylinder; 3 round support. 
The principle of operation of a stabilizer is the following: when the action that causes deviation occurs the plug rotates to a specified angle about the pneumodrift axis. In this case a stabilizing moment occurs caused by eccentric action of impact load which tends to bring the plug in its initial position and the pneumodrift - to the set direction. Use of stabilizers enables to expect higher accuracy of drilling direction, especially for boreholes of small length $(25-30 \mathrm{~cm})$. For longer boreholes the efficiency of such method decreases due to progressive increase of error [11].

The most effective solution of the drilling accuracy issue consists in providing technical means for controlled change of drilling trajectory of the operating tool in soil. It can be independently moving pneumodrifts that are capable of changing drilling trajectory by operator's command [12, 13], as well as static borehole piercing equipment (Fig.1). However, today there is no serial production of controllable pneumodrifts which are currently represented by prototypes.

Reasonable solution to provide control of the trajectory and increase of the borehole piercing speed is a combination of static and dynamic action on the operating tool that forms a pilot hole. To control the borehole trajectory, an impact action tool shall be installed in the front part of the drill pipe, such as a pneumodrift with a wedge bit.

\section{Experimental data and results}

The studies $[8,14]$ demonstrate that a combination of static and dynamic actions applied to the tool that penetrates soil enables to enhance the forward movement by impact pulse actions and to reduce its return caused by elastic component of soil response after impact pulse action. As a result of calculations, the authors defined the dependency for the movement rate of the operating tool with a head installed on the front part of a pneumodrift and forming the hole of $325 \mathrm{~mm}$ in diameter on the static action applied to the pneumodrift body transmitted via drill string. The energy of impact pulses is $600 \mathrm{~J}$ and the frequency of pulses is $5 \mathrm{~Hz}$.

The calculation was based on the known solution of the task of equilibrium state of annular soil layer with core loaded cavity suggested by Prof. Dr. A.L. Isakov for describing the dynamics of the tool movement while borehole reaming $[15,16]$.

The solution was obtained witht he following assumptions:

1. Plane section hypothesis is applied when describing the process of soil cavity expansion, i.e. it is assumed that the movement trajectory of the compacting soil particles lies in the planes perpendicular to the axis of reamed borehole.

2. Under pulse loading soil compaction from initial to final density occurs in a jumplike manner under the pressure that reached some critical value. Behind the compaction wave front soil behaves like a plastically deformed body.

At the first stage the distance of the operating tool movement under single action of the impact pulse was defined, then movement rate was defined with the account of impact actions frequency. 


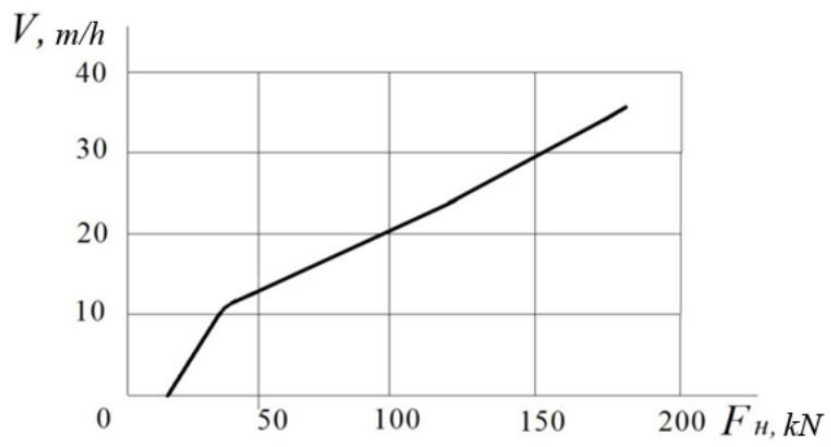

Fig. 3. Dependency of tool penetration rate on static action for various structure of impact energy.

The defined dependency is graphically represented in Figure 3. It is seen that the movement of operating tool is observed only for some initial value of static load, below this level the impact pulse energy is insufficient for overcoming the elastic component of soil resistance. Consequently, plastic deformation of soil is impossible to occur. Under further growing static action the drilling rate soars as the efficiency of impact pulse actions increases due to lower uncompensated share of elastic soil response. As soon as static action reaches the value of $35-40 \mathrm{kN}$ the intensity of drilling rate growth significantly decreases. In this zone static action completely compensates for soil elastic response and all impact pulse energy is spent on plastic deformation of soil and forward movement of the tool. Here the capability of increasing impact efficiency is exhausted. Further increase of rate occurs less intensively and is caused exclusively by growing static action.

For the purpose of experimental verification of the results obtained with ИП-4603 serial pneumodrift an operating tool was produced for pilot hole drilling by directed piercing. To perform that the front side of pneumodrift installed in a drill string was equipped with a wedge bit. The rear part of the body was retrofitted to provide connection with the drill string. The joint is an important element of the drilling equipment which transmits static axle load and torque to the operating tool. Special spline connection was developed which enables axle mobility of the pneumodrift in relation to drill string. It allows preventing the possibility of transmitting impact pulses to the drill string, destruction of this connection or pneumodrift body, as well as reversing the impact mechanism when changing the direction of a drilling unit for easier reverse motion.

Design scheme of the operating tool with the use of retrofitted ИП-4603 pneumodrift is presented in Figure 4.

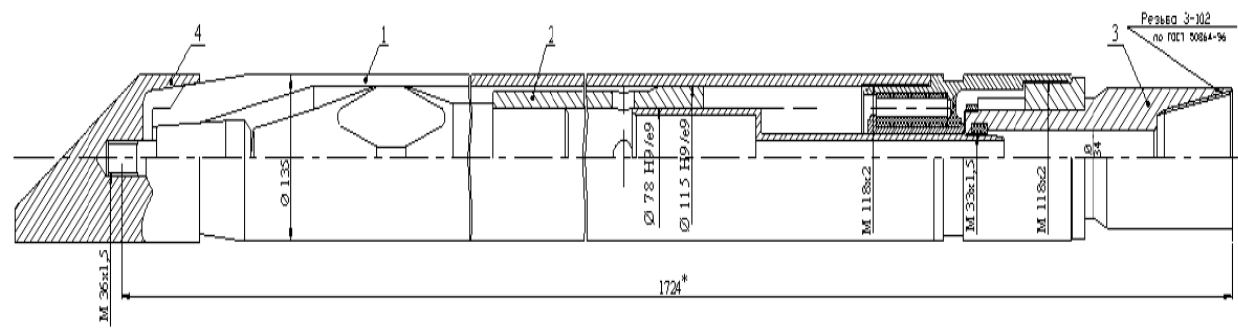

Fig. 4. Operating tool for pilot hole combined drilling: 1 - body; 2 - striker; 3 - joint; 4 - deflecting mechanism. 
Experiments were preformed on the "Green Hill" testing ground of Institute of Mining, Siberian Branch of Russian Academy of Sciences. At the first stage of experiments pilot holes were drilled using directed dynamic piercing method in combination with static load. It was determined that the amount of static load can be reduced up to 2 times in comparison with static piercing method. This fact significantly simplifies the task of drilling machine bolting and allows reducing its power. The tendency of drilling rate change for various combinations of impact power and static load was revealed both experimentally and by calculations. However, the amount of effect obtained in all experiments appeared to be smaller by $25-30 \%$.

Analysis of the obtained results demonstrates that important factors for high borehole drilling rate are amount of static and pulse load, as well as the rate of drill string forward movement. The rate shall be sufficient for the elastic deformation phase of soil to finish within the pause between two impacts. Then, all energy of impact pulse will perform useful work on plastic deformation and forward movement of the tool.

The process of interaction between the pneumodrift body and soil was previously studied at the Institute of Mining, Siberian Branch of the Russian Academy of Sciences [17], as a result a dependency was obtained for movement of the operating tool body under impact pulse action and after it (Fig.5).

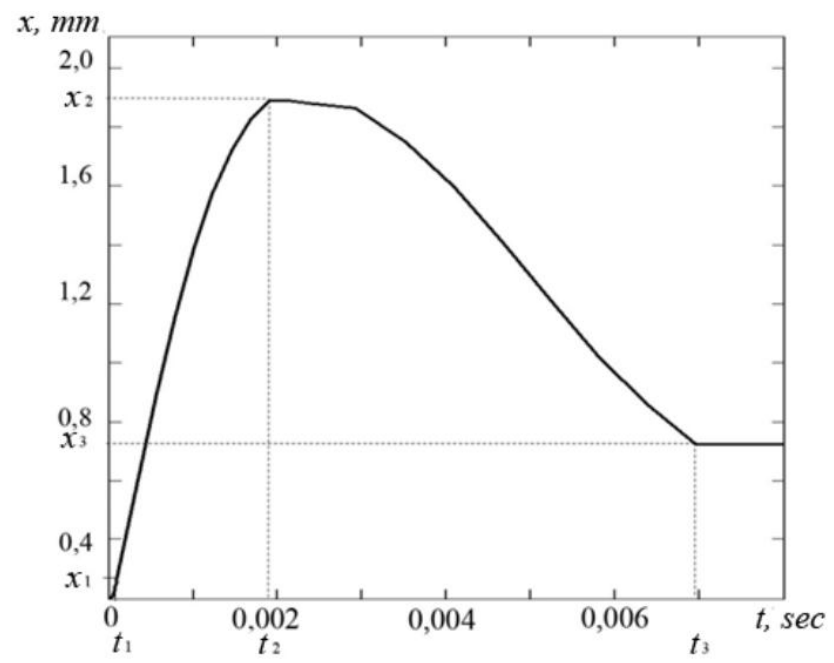

Fig. 5. Dependency of pneumodrift movement distance on the time of impact action: $t_{1}$ - end time of impact action and start of movement; $t_{2}$ - end time of forward movement; $t_{3}$ - end time of return.

The graph shows that the process of pneumodrift movement has mostly dynamic nature. Within the period of $0.002 \mathrm{sec}$ the movement distance is $1.75 \mathrm{~mm}$, and the average rate is $0.9 \mathrm{~m} / \mathrm{sec}$. After the impact action finishes the body stops under the effect of soil elastic response and return movement begins. To enhance impact efficiency the tool shall be moved forward before the next pulse impact begins. This way, a pneumodrift shall move approximately $1 \mathrm{~mm}$ forward due to static action. With impact frequency of 5 to $10 \mathrm{~Hz}$ it shall cover this distance for $0.2-0.1 \mathrm{sec}$. Consequently, the rate shall be within the range of $0.005-0.01 \mathrm{~m} / \mathrm{sec}$.

The simplest and the most efficient solution of the stated problem consists in using an intermediate element like elastic linkage for connecting the drill string and the operating tool. The main function of this element is preliminary storage of deformation energy in pauses between impacts and output of this energy for moderation of elastic soil response immediately after the impact. 
During field experiments with the suggested design it was determined that it enables to drill pilot holes in compacting soil using a combination of force actions with the capability of compensation of the trajectory deviation up to $0.1 \mathrm{~m}$ on the length of less than $2 \mathrm{~m}$. This result is accepted for solving practical tasks.

\section{Conclusion}

Piercing is the simplest and the most technologically advanced technique of pilot hole drilling. The results of this research showed that significant increase in the borehole drilling rate using vibro-impact operating tool is achieved due to simultaneous application of pulse impact and static loads. This effect is obtained without increase in impact pulse energy by enhancing efficiency of its operation. For experimental verification and assessment of the expected effect the operating tool based on serial pneumodrift was designed and retrofitted for operation with a drilling unit. The experiments demonstrated that such technology enables implementation of highly efficient method of vibro-impact piercing and provides accuracy of a borehole location in the defined underground area due to control and corrections in the trajectory while drilling. This proves high perspective of development of such technology. In order to provide complete implementation of its capabilities further research on the process of interaction between the operating tool and soil are required aimed at decreasing impact energy losses on elastic deformation of soil.

\section{References}

1. B.B. Danilov, B.N. Smolyanitskiy, Journal of Fundamental and Applied Mining Sciences, Vol. 2, 1, 104-113 (2014). (in Russian)

2. B. Maidl, L. Schmid, W. Ritz, M. Herrenknecht, Hardrock Tunnel Boring Machines (Ernst \& Sohn, Berlin, 2008).

3. G. Deng, A. Yao, Proceedings of the 19th EGU General Assembly, EGU2017, (Vienna, Austria, 23-28 April, 2017).

4. K. Fallwell, Tunnels and Tunnelling International, (June), 45-50 2015).

5. A.P. Rybakov, Osnovy bestranshejnyh tehnologij [Fundamentals of trenchless technologies] (Press-Buro, Moscow, 2005). (in Russian)

6. C. Kummerer, Proceedings of the XVI European Conference on Soil Mechanics and Geotechnical Engineering, ECSMGE 2015, 2 619-624 (2015).

7. B.B. Danilov, B.N. Smolyanitskiy, Proceedings of the Research-to-Practice Conference "Safety and Efficiency Problems of geo-resources development in present conditions", 195 - 201 (Perm, 2014). (in Russian)

8. B.N. Smolyanitskiy, B.B. Danilov, Polytransport Systems: Proceedings of the VIII International Scientific and Technical Conference, 718-723 (STU Publ., Novosibirsk, 2014). (in Russian)

9. E. Schey, J. Chae, Proceedings of the Pipelines 2013 Conference, 875-883 (2013).

10. W. Norhaliza, B. Ismail, A.T.S. Azhar, N.J. Nurul, IOP Conf. Series: Materials Science and Engineering, 136, 012018 (2016).

11. K.S. Gurkov, V.V. Klimashko, A.D. Kostylev, V.D. Plavskikh, K.K. Tupitsyn, Pnevmoprobojniki [Pneumodrifts] (Novosibirsk, 1990). (in Russian)

12. Allied Hole-Hog underground piercing tools, (Allied Steel \& Tractor Products Inc., 1982).

13. B.B. Danilov, D.O. Cheshchin, Polytransport Systems: Proceedings of the VIII International Scientific and Technical Conference, 724-728 (STU Publ., Novosibirsk,, 2014). (in Russian) 
14. B.B. Danilov, A.S. Kondratenko, B.N. Smolyanitskiy, A.S. Smolentsev, Fizikotehnicheskie problemy razrabotki poleznyh iskopaemyh [Journal of Mining Science] 3, 57 - 64 (2017). (in Russian)

15. A.L. Isakov, A.K. Tkachuk, Fiziko-tehnicheskie problemy razrabotki poleznyh iskopaemyh [Journal of Mining Science], 2 (2000). (in Russian)

16. A.L. Isakov, A.E. Zemtsova, Fiziko-tehnicheskie problemy razrabotki poleznyh iskopaemyh [Journal of Mining Science], 3, 95 - 100 (1998). (in Russian)

17. A.A. Repin, Dinamics and Strength of Mining Machines, 160 - 161 (2001). (in Russian) 